\title{
Assessment the Association of Fatty Acid Binding Protein 1 with Hepatocellular Carcinoma
}

\author{
Reda M. Albadawy ${ }^{\text {a }}$, Badawy A. Abd El-Aziz ${ }^{\text {a }}$, Eman G. Behiry ${ }^{\text {b }}$, Maha E. Azzam ${ }^{\text {a }}$
}

\begin{abstract}
Department of Hepatology, Gastroentrology and Infectious Diseases, Benha faculty of medicine, Benha University, Egypt. ${ }^{\mathrm{b}}$ Department Clinical and Chemical Pathology, Benha Faculty Of Medicine ,Benha University, Egypt
\end{abstract}

Correspondence to: Maha E. Azzam, Department of Hepatology, Gastroentrology and Infectious Diseases Benha faculty of medicine, Benha University, Egypt.

Email:

doctorhepatology@gmail.com

Received: 14 November 2019

Accepted: 19 January 2020

\begin{abstract}
Background \& Objectives: Hepatocellular carcinoma and its complications with the multiplicity is crucial worldwide health problem especially in the presence of heterogeneous liver. We aimed to assess the value of fatty acid binding protein-1in the diagnosis of hepatocellular carcinoma in comparison to alpha-fetoprotein. Methodology: One hundred subjects were enrolled in this observational case-control study who attended the Hepatology, Gastroenterology and Infectious Diseases Department in Benha University Hospitals between January 2018 and January 2019 and divided into 80 patients (40 HCC \&40 LC and 20 healthy subjects). Serum level of fatty acid binding protein-1 was determined by enzymelinked immunosorbent assay. Results: Hepatocellular carcinoma patients were slightly older than healthy subjects as mean age in group I was $(56.1 \pm 9 \mathrm{yrs})$ while in group III was $(52.9 \pm 17.1 \mathrm{yrs})$. There was a marked increase in hepatocellular carcinoma in males with male to
\end{abstract}

female ratio 4:1. There was a high prevalence of hepatocellular carcinoma in the rural population.

Fatty acid binding protein-1 was higher in hepatocellular carcinoma compared to liver cirrhosis and the control group, ranged from (107-1224 ng/L, 48-981 ng/L and 34-460 ng/L) respectively. Analysis of ROC curve revealed that at a level $214 \mathrm{ng} / \mathrm{L}$ sensitivity, specificity, PPV, NPV and accuracy were $60 \%, 77.5 \%, 72.7 \%, 66 \%$ respectively with AUC 0.715 Conclusion: The use of fatty acid binding protein-1especially in multicentric hepatocellular carcinoma will be valuable because the difficulty in most cases to prove the multplicity of hepatocellular carcinoma.

Key Words: Hepatocellular Carcinoma (HCC), Fatty Acid Binding Protein (FABP-1), liver cirrhosis (LC) 


\section{Introduction}

Hepatocellular carcinoma (HCC) is the fifth most common tumour worldwide and the second most common cause of cancerrelated death (1). It is one of the most common aggressive malignancies worldwide; accounting about two thirds of all primary liver cancer cases (2). Liver fatty acid-binding proteins (LFABPs) are a group of low molecular weight (14-15 kDa) proteins involved in the intracellular transport of long-chain bioactive fatty acids. FABPs should promise to serve as markers of tissue injury. Various FABPs were tested to detect early damage of tissues with probability of its clinical usage (3).

L-FABP is an important endogenous cytoprotectant, minimizing hepatocyte oxidative damage and interfering with ischemia-reperfusion and other hepatic injuries (4).L-FABP has been reported in many metabolic disease processes, such as cholestatic liver disease, cancer, diabetes, obesity and atherosclerosis (5).Over expression of L-FABP has been observed in various cancers, including liver, lung, gastric, and colon cancers (6).L-FABP was highly expressed in the tumor tissue as in HCC malignancy and could serve as a potential target for HCC therapy (7).
We aimed to assess the value of fatty acid binding protein-1 in the diagnosis of hepatocellular carcinoma in comparison to Alpha-fetoprotein.

\section{Subjects and Methods}

This observational case-control study was conducted on 100 subjects attending Department of Hepatology, Gastroentrology and Infectious Diseases in Benha University Hospitals during the period from January 2018 to January 2019 and informed written consent was obtained from all patients participating in this study after explaining the study measures in details and divided into three groups Group I Included 40 patients with hepatocellular carcinoma, Group II Included 40 patients with cirrhosis and Group III Included 20 apparently healthy subjects as control group.

Patients with HCC received any type of treatment, patients with malignancies other than HCC, patients with acute kidney injury, heart failure, pneumonia and patient with chronic HBV were excluded. Full history taking and thorough clinical examination and laboratory tests including $\mathrm{CBC}$, blood sugar level, serum ALT, serum AST, serum creatinine, viral markers ( $\mathrm{HBsAg}$, anti-HCV 
Ab) were assayed using 3rd generation enzyme linked immunosorbent assay (ELISA)Kit, alpha fetoprotein (AFP) (ng/dl) by (ELISA)and serum fatty acid binding protein-1(FABP-1 ng/L): FABP-1 was measured with a sandwich enzyme-linked immunosorbent assay developed in collaboration with Sunshine Biotechnology.
The detection limit of the assay was $(8 \mathrm{ng} / \mathrm{L}-$ 2000ng/L). Imaging by 4-phase multidetector CT scan or dynamic contrast enhanced MRI for diagnosis of HCC by identification of the typical hallmark (hypervascularity in arterial phase with washout in the portal venous or delayedphases) (EASL- EORTC, 2012).

Okuda staging system was used to assess the stage of HCC.

\begin{tabular}{lll} 
& \multicolumn{1}{c}{ Points } \\
\cline { 2 - 3 } & 0 & 1 \\
\hline Tumour size & $<50 \%$ of liver & $>50 \%$ of liver \\
Ascites & No & Yes \\
Albumin $(\mathrm{g} / \mathrm{dl})$ & $\geqslant 3$ & $<3$ \\
Bilirubin $(\mathrm{mg} / \mathrm{dl})$ & $<3$ & $\geqslant 3$ \\
\hline Okuda stage I, O points; Okuda stage II, I or 2 points; Okuda stage III, 3 \\
or 4 points.
\end{tabular}

\section{Statistical Analysis}

The analysis of the data was carried out using SPSS (IBM Corp. Released 2011. IBM SPSS Statistics for Windows, version 20.0. Armonk, NY: IBM Corp.). Categorical data were presented as number and percentages while quantitative data were expressed as mean \pm standard deviation Median, Fisher-exact test (FET) was used to analyze categorical variables. Student " $t$ " test was used to analyze normally distributed variables among 2 independent groups. ChiSquare test was used to examine the relationship between two qualitative variables. Difference among 3independent means was analyzed using ANOVA for parametric variables. The Mann-Whitney (U-test) used to compare two nonparametric quantitative variables, $\quad \mathrm{p}<0.05$ was 
considered statistically significant.The ROC Curve (receiver operating characteristic) provides a useful way to evaluate the sensitivity and specificity for quantitative diagnostic measures that categorize cases into one of two groups. The optimum cut off point was defined as that which maximized the AUC value. The area under the ROC curve (AUC) results were considered excellent for AUC value between 0.9-1, good for AUC values between 0.8-0.9, fair for AUC values between 0.7-0.8, poor for AUC values between 0.6-0.7 and failed for AUC values between 0.5-0.6 .

\section{Results:}

The present history and clinical examination were summarized in HCC was significantly associated with weight loss, while LC was significantly associated with history of ascites, HE and edema LL. Otherwise, no significant differences were found between the two groups.

\section{As regard laboratory investigations:}

Hemoglobin concentration and platelet count were significantly lower in LC and HCC when compared to healthy control group as mean levels of hemoglobin and platelets were $(10.1 \pm 3.3,9.7 \pm 1.7,11.9 \pm 0.6)$, $(77.6 \pm 17.8 \quad, \quad 77.2 \pm 16.7, \quad 283.4 \pm 37.2)$ respectively. There were significantly higher s. ALT, s. AST, s, bilirubin, INR, PT, s.AFP and significantly lower s.albumin concentration between HCC and LC groups when compared to healthy control group. HCC showed significantly higher concentration of serum alpha-fetoprotein when compared to LC group. Otherwise, no significant differences were found in liver function tests between both groups.

Also, there was a highly statistically significant difference between studied groups as regard fatty acid binding protein-1 level it was significantly higher in LC and HCC when compared to control groups. Moreover, it was higher in HCC when compared to LC groups ranged from (107$1224 \mathrm{ng} / \mathrm{l}, \quad 48-981 \mathrm{ng} / \mathrm{l}$ and 34-120 ng/l) respectively.

\section{As regard ultrasonographic examination among LC and HCC groups:}

Narrower portal vein diameter, as well as portal vein thrombosis were significantly associated with HCC when compared to LC groups with mean values(9.6 $\pm 3.1,13.3 \pm 2.2) \quad$ respectively. Otherwise no significant differences were found in liver size, spleen and ascites grades between HCC and LC groups 
As regard CT Criteria of hepatic focal lesions in all studied HCC cases:

$(87.5 \%)$ of focal lesions were single and $(12.5 \%)$ were multiple. They were located mostly in right lobe in $(80 \%)$. As regarding size $90 \%$ of them were more than $3 \mathrm{~cm}$ and $92.5 \%$ of them were hypodense in echogenicity.

Table (1): Comparison of clinical data (present history and clinical examination) among LC and HCC groups

\begin{tabular}{|c|c|c|c|c|c|}
\hline & \multirow{2}{*}{\multicolumn{2}{|c|}{$\begin{array}{c}\text { Group I (HCC) } \\
\qquad \mathbf{N}=\mathbf{4 0}\end{array}$}} & \multicolumn{2}{|c|}{ Group II (LC) } & \multirow{3}{*}{$P$} \\
\hline & & & & & \\
\hline & $\mathbf{N}$ & $\%$ & $\mathbf{N}$ & $\%$ & \\
\hline Abdominal pain & 23 & 57.5 & 19 & 47.5 & $0.370^{\mathrm{C}}$ \\
\hline Abdominal discomfort & 32 & 80 & 34 & 85 & $0.556^{\mathrm{C}}$ \\
\hline Weight loss & 12 & 30 & 1 & 2.5 & $0.001^{\mathrm{C}}$ \\
\hline History of abdominal pain & 26 & 65 & 25 & 62.5 & $0.816^{\mathrm{C}}$ \\
\hline Bleeding & 15 & 37.5 & 14 & 35 & $0.816^{\mathrm{C}}$ \\
\hline History of ascites & 24 & 60 & 33 & 82.5 & $0.026^{\mathrm{C}}$ \\
\hline Encephalopathy & 7 & 17.5 & 14 & 35 & $0.075^{\mathrm{C}}$ \\
\hline Fever & 5 & 12.5 & 6 & 15 & $0.745^{\mathrm{C}}$ \\
\hline Sclerotherapy & 6 & 15 & 6 & 15 & $1.000^{\mathrm{C}}$ \\
\hline Band ligation & 17 & 42.5 & 16 & 40 & $0.820^{\mathrm{C}}$ \\
\hline Pallor & 17 & 42.5 & 23 & 57.5 & $0.180^{\mathrm{C}}$ \\
\hline Jaundice & 21 & 52.5 & 29 & 72.5 & $0.065^{\mathrm{C}}$ \\
\hline \multirow{4}{*}{ Hepatic encephalopathy } & 9 & 22.5 & 19 & 47.5 & \multirow{4}{*}{$0.003^{\mathrm{F}}$} \\
\hline & 31 & 77.5 & 9 & 22.5 & \\
\hline & 0 & 0 & 1 & 2.5 & \\
\hline & 0 & 0 & 1 & 2.5 & \\
\hline Flapping tremors & 8 & 20 & 14 & 35 & $0.133^{\mathrm{C}}$ \\
\hline Clubbing & 3 & 7.5 & 0 & 0 & $0.241^{\mathrm{F}}$ \\
\hline LL edema & 26 & 65 & 36 & 90 & $0.007^{\mathrm{C}}$ \\
\hline
\end{tabular}

C : chi square test F: Fisher exact test 
Benha medical journal vol. 38, isuue 1, 20201

Table (2): Comparison of laboratory investigations among studied groups.

\begin{tabular}{|c|c|c|c|c|c|c|c|c|}
\hline & & $\begin{array}{l}\text { Group I } \\
\text { (HCC) } \\
\mathbf{N}=\mathbf{4 0} \\
\end{array}$ & $\begin{array}{l}\text { Group II } \\
\text { (LC) } \\
\mathrm{N}=\mathbf{4 0} \\
\end{array}$ & $\begin{array}{l}\text { Group III } \\
\text { (Control) } \\
\mathbf{N = 2 0} \\
\end{array}$ & $P^{I}$ & $P^{2}$ & $P^{3}$ & $P^{4}$ \\
\hline HB(g/dL) & mean \pm SD & $10.1 \pm 3.3$ & $9.7 \pm 1.7$ & $11.9 \pm 0.6$ & $0.005^{\mathrm{A}}$ & $0.001^{\mathrm{T}}$ & $0.009^{\mathrm{T}}$ & $0.428^{\mathrm{T}}$ \\
\hline $\begin{array}{l}\text { WBCs } \\
\left(\mathbf{X 1 0}^{9} / \mathrm{L}\right)\end{array}$ & mean \pm SD & $7.8 \pm 1.2$ & $5.8 \pm 1.6$ & $6.4 \pm 1.3$ & $0.322^{\mathrm{A}}$ & $0.721^{\mathrm{T}}$ & $0.390^{\mathrm{T}}$ & $0.139^{\mathrm{T}}$ \\
\hline $\begin{array}{l}\text { Platelets } \\
\left(\times 10^{9} / \mathrm{L}\right)\end{array}$ & mean \pm SD & $77.6 \pm 17.8$ & $77.2 \pm 16.7$ & $283.4 \pm 37.2$ & $<0.001^{\mathrm{A}}$ & $<0.001^{\mathrm{T}}$ & $<0.001^{\mathrm{T}}$ & $0.974^{\mathrm{T}}$ \\
\hline $\begin{array}{l}\text { FBG } \\
(\mathrm{mg} / \mathrm{dL})\end{array}$ & mean \pm SD & $93 \pm 30.1$ & $118.4 \pm 32.6$ & $85.8 \pm 8.1$ & $0.205^{\mathrm{A}}$ & $0.107^{\mathrm{T}}$ & $0.641^{\mathrm{T}}$ & $0.086^{\mathrm{T}}$ \\
\hline $\begin{array}{l}\text { Creatinine } \\
(\mathrm{mg} / \mathrm{dL})\end{array}$ & mean \pm SD & $1.2 \pm 0.4$ & $1.2 \pm 0.3$ & $0.8 \pm 0.1$ & $0.213^{\mathrm{A}}$ & $0.104^{\mathrm{T}}$ & $0.113^{\mathrm{T}}$ & $0.645^{\mathrm{T}}$ \\
\hline $\operatorname{ALT}(\mathbf{I} / \mathbf{U})$ & mean \pm SD & $48.3 \pm 12.2$ & $52.2 \pm 15.5$ & $25.6 \pm 2.7$ & $0.013^{\mathrm{A}}$ & $0.004^{\mathrm{T}}$ & $0.015^{\mathrm{T}}$ & $0.597^{\mathrm{T}}$ \\
\hline $\operatorname{AST}(\mathbf{I} / \mathbf{U})$ & mean \pm SD & $66.7 \pm 20.8$ & $65.4 \pm 15.2$ & $24.8 \pm 6.1$ & $<0.001 \mathrm{~A}$ & $<0.001 \mathrm{~T}$ & $<0.001 \mathrm{~T}$ & $0.872 \mathrm{~T}$ \\
\hline $\begin{array}{l}\text { Bilirubin } \\
(\mathrm{mg} / \mathrm{dL})\end{array}$ & $\begin{array}{l}\text { Median } \\
\text { min-max }\end{array}$ & $\begin{array}{l}2 \\
1-17\end{array}$ & $\begin{array}{l}3 \\
1-10\end{array}$ & $\begin{array}{l}0.9 \\
0.8-1.3\end{array}$ & $0.001^{\mathrm{K}}$ & $<0.001^{\mathrm{M}}$ & $0.001^{\mathrm{M}}$ & $0.652 \mathrm{~T}^{\mathrm{M}}$ \\
\hline $\begin{array}{l}\text { Albumin } \\
\text { (g/dL) }\end{array}$ & mean \pm SD & $2.8 \pm 0.7$ & $2.4 \pm 0.6$ & $4.4 \pm 0.5$ & $<0.001^{\mathrm{A}}$ & $<0.001^{\mathrm{T}}$ & $<0.001^{\mathrm{T}}$ & $0.213^{\mathrm{T}}$ \\
\hline INR & mean \pm SD & $1.6 \pm 0.5$ & $1.5 \pm 0.5$ & $1 \pm 0.2$ & $<0.001^{\mathrm{A}}$ & $<0.001^{\mathrm{T}}$ & $<0.001^{\mathrm{T}}$ & $0.500^{\mathrm{T}}$ \\
\hline PT (s) & $\operatorname{mean} \pm \mathrm{SD}$ & $16.7 \pm 3$ & $15.9 \pm 2.3$ & $12.4 \pm 0.5$ & $<0.001^{\mathrm{A}}$ & $<0.001^{\mathrm{T}}$ & $<0.001^{\mathrm{T}}$ & $0.141^{\mathrm{T}}$ \\
\hline $\begin{array}{l}\text { AFP } \\
(\mathrm{ng} / \mathrm{mL})\end{array}$ & $\begin{array}{l}\text { Median } \\
\text { min-max }\end{array}$ & $\begin{array}{l}268 \\
1-13588\end{array}$ & $\begin{array}{l}7.5 \\
1-62\end{array}$ & $\begin{array}{l}0.4 \\
0.05-5\end{array}$ & $0.012^{\mathrm{K}}$ & $<0.001^{\mathrm{M}}$ & $<0.001^{\mathrm{M}}$ & $0.002^{\mathrm{M}}$ \\
\hline $\begin{array}{l}\text { FABP-1 } \\
(\mathrm{ng} / \mathrm{L})\end{array}$ & $\begin{array}{l}\text { Median } \\
\text { Minimum } \\
\text { maximum }\end{array}$ & $\begin{array}{l}260.5 \\
107 \\
1224\end{array}$ & $\begin{array}{l}171.5 \\
48 \\
981\end{array}$ & $\begin{array}{l}40 \\
34 \\
120\end{array}$ & $<0.001^{\mathrm{K}}$ & $<0.001^{\mathrm{M}}$ & $<0.001^{\mathrm{M}}$ & $0.001^{\mathrm{M}}$ \\
\hline
\end{tabular}

M: Mann Whitney K: Kruskal Wallis test. T: student t test A: ANOVA 
Table (3): Comparison of ultrasonographic examination among LC and HCC groups.

\begin{tabular}{|c|c|c|c|c|c|c|}
\hline & & \multicolumn{2}{|c|}{$\begin{array}{c}\text { Group I (HCC) } \\
\mathbf{N}=\mathbf{4 0}\end{array}$} & \multicolumn{2}{|c|}{$\begin{array}{c}\text { Group II (LC) } \\
\qquad=\mathbf{4 0}\end{array}$} & \multirow{2}{*}{$P$} \\
\hline & & $\mathbf{N}$ & $\%$ & $\mathbf{N}$ & $\%$ & \\
\hline \multirow{3}{*}{ Liver size } & Enlarged & 9 & 22.5 & 2 & 5 & \multirow{3}{*}{$0.193^{\mathrm{F}}$} \\
\hline & Average & 23 & 57.5 & 19 & 47.5 & \\
\hline & Shrunken & 8 & 20 & 9 & 22.5 & \\
\hline \multirow{3}{*}{ liver texture } & Normal & 0 & 0 & 0 & 0 & \multirow{3}{*}{$0.107^{\mathrm{F}}$} \\
\hline & Coarse & 17 & 42.5 & 13 & 32.5 & \\
\hline & Cirrhotic & 20 & 50 & 27 & 67.5 & \\
\hline \multirow{3}{*}{ Spleen } & Normal & 10 & 25 & 4 & 10 & \multirow{3}{*}{$0.139^{\mathrm{F}}$} \\
\hline & Splenomegaly & 30 & 75 & 35 & 87.5 & \\
\hline & Removed & 0 & 0 & 1 & 2.5 & \\
\hline \multirow{2}{*}{ Ascites } & Absent & 13 & 32.5 & 1 & 2.5 & \multirow{2}{*}{$<0.001^{\mathrm{C}}$} \\
\hline & Present & 27 & 67.5 & 39 & 97.5 & \\
\hline \multirow{3}{*}{ Ascites grades } & minimal & 5 & 12.5 & 15 & 37.5 & \multirow{3}{*}{$0.179^{\mathrm{C}}$} \\
\hline & Moderate & 14 & 35 & 13 & 32.5 & \\
\hline & tense & 8 & 20 & 11 & 27.5 & \\
\hline \multirow{2}{*}{ PV patency } & Patent & 30 & 75 & 40 & 100 & \multirow{2}{*}{$<0.001$} \\
\hline & Thrombosis & 10 & 25 & 0 & 0 & \\
\hline PV diameter (mm) & $\operatorname{mean} \pm \mathrm{SD}$ & \multicolumn{2}{|c|}{$9.6 \pm 3.1$} & & $13.3 \pm 2.2$ & $<0.001^{\mathrm{T}}$ \\
\hline
\end{tabular}

$\mathrm{C}$ : chi square test $\mathrm{F}$ : Fisher exact test $\mathrm{T}$ : student $\mathrm{t}$ test

Table (4): CT Criteria of hepatic focal lesions in all studied HCC cases .

\begin{tabular}{llcc}
\hline & & Group I (HCC) & $\mathbf{N}=\mathbf{4 0}$ \\
& & $\mathbf{N}$ & $\%$ \\
\hline \multirow{2}{*}{ Multiplicity } & Single & 35 & $\mathbf{8 7 . 5}$ \\
& multiple & 5 & 12.5 \\
Site & Right lobe & 32 & $\mathbf{8 0}$ \\
& Left lobe & 3 & 7.5 \\
Size (cm) & Both lobes & 5 & 12.5 \\
& $<\mathbf{2}$ & 2 & 5 \\
Echogenicity & $\mathbf{2 - 3}$ & 2 & 5 \\
& $>\mathbf{3}$ & 36 & $\mathbf{9 0}$ \\
Homogeneity & Hyperdense & 1 & 2.5 \\
Positive rapid wash out & Hypodense & 37 & $\mathbf{9 2 . 5}$ \\
Arterial phase enhancement & Isodense & 2 & 5 \\
& Non homogenous & 12 & 30 \\
& Homogenous & 28 & 70 \\
& & 40 & 100 \\
\end{tabular}


Table (5): Diagnostic performances of FABP for discrimination between HCC and LC cases.

\begin{tabular}{lcccccccc}
\hline & AUC & $\mathbf{9 5 \%} \mathbf{C I}$ & $\mathbf{P}^{\mathbf{1}}$ & Cut off & $\begin{array}{c}\text { Sensitivity } \\
(\boldsymbol{\%})\end{array}$ & $\begin{array}{c}\text { Specificity } \\
(\boldsymbol{\%})\end{array}$ & PPV (\%) & $\begin{array}{c}\text { NPV } \\
(\%)\end{array}$ \\
\hline FABP-1 & 0.715 & $0.603-0.827$ & 0.001 & 214 & 60 & 77.5 & 72.7 & 66 \\
\hline
\end{tabular}

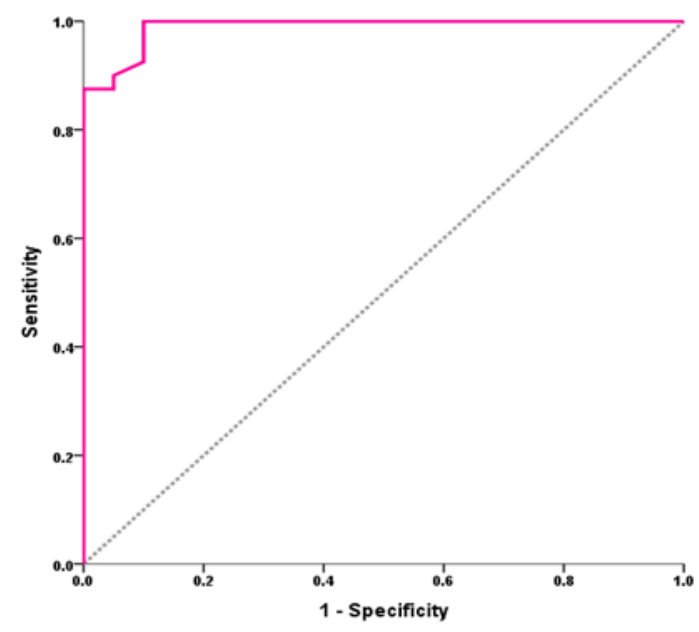

Figure (1): ROC curve of serum FABP for discrimination between HCC cases and control group.

\section{Discussion}

In Egypt, liver cancer counts for $11.75 \%$ of the malignancies of the digestive organs and $1.68 \%$ of the total malignancies. HCC forms $70.48 \%$ of all liver tumors among Egyptians and it is considered the main complication of cirrhosis, and represents a growing incidence in Egypt, which may be due to a shift in the relative importance of ( $\mathrm{HBV}$ ) and $\mathrm{HCV}$ as primary risk factors, and advancements in screening programs and diagnostic materials (8). The present history and clinical examination were summarized in Table 1. HCC was significantly associated with weight loss, while LC was significantly associated with history of ascites. Abdominal pain was found in $57.5 \%$ of HCC cases .These results were in agreement with (9) who stated that pain in HCC patients is a frequent complaint and also, (10) found that new onset abdominal 
pain in a cirrhotic patient should raise the possibility of HCC. Otherwise, no significant differences were found between the two groups.

Hemoglobin concentration and platelet count were significantly lower in LC and HCC when compared to healthy control group as mean levels of Hemoglobin and platelets were $(10.1 \pm 3.3,9.7 \pm 1.7,11.9 \pm 0.6)$, $(77.6 \pm 17.8, \quad 77.2 \pm 16.7, \quad 283.4 \pm 37.2)$ respectively. This was in agreement with (11) who demonstrated that most of patients with HCC were anemic when they are first seen, although severe anemia is rare and should suggest the possibility of intraperitoneal bleeding. Most cases of HCC are accompanied by liver cirrhosis. Liver cirrhosis could ultimately lead to portal hypertension and hypersplenism and cause a subsequent decrease in platelet count (12).

There were significantly higher ALT, AST, bilirubin, INR, PT, AFP and significantly lower albumin concentration between HCC and LC groups when compared to healthy control group. Significant marked increase in bilirubin , mild increase in AST and ALT in HCC patients was explained as being due to the impaired ability of damaged and necrosed hepatocytes to release conjugated bilirubin in addition to the leakage of hepatic enzymes through its inflamed wall (13). Moreover, serum albumin was significantly lower and PT and INR were significantly higher in HCC patients. This could be attributed to the impaired synthetic ability of the liver for albumin and vitamin $\mathrm{K}$, the co-factor of extrinsic coagulation pathway $(14,15)$.

FABP-1 level was significantly higher in LC and HCC when compared to control groups. Moreover, it was higher in HCC when compared to LC groups, this was in agreement with (16) who found that serum FABP-1 levels were 2-fold higher in the presence of HCC compared with the absence of HCC.

This also came in agreement with a study where it was reported thatFABP-1 was significantly up-regulated in HCC patients with and without cirrhosis. Moreover, in the cirrhosis patients, high FABP-1 expression was related to a higher risk of poor survival (17)

\section{As regard ultrasonographic examination} about $92.5 \%$ of the patients with HCC had sonographic evidence of liver cirrhosis .This was in agreement with other studies, who stated that, in all parts of the world HCC frequently coexists with cirrhosis 
$(18,19)$ and with another study that stated that liver cirrhosis is a well-known risk factor for the development of HCC (20). This is supported also by other researchers who documented that cirrhosis of the liver is present in 60 to $100 \%$ of patients with HCC (21)

Ten patients $(25 \%)$ in this study were found to have portal vein thrombosis. This finding was in agreement with a study which reported portal vein thrombosis in $(11.9 \%)$ of cases (22). A higher finding was reported by others who reported $(28.2 \%),(18 \%)$ of cases had portal vein thrombosis respectively $(23,24)$.

In the current study different patterns of focal lesions as regards number, echogenicity and location were detected with no specific predilection. Single hepatic focal lesions were detected in $87.5 \%$ of patients and multiple focal lesions in $12.5 \%$ of patients. $92.5 \%$ of the focal lesions were of hypodense pattern. This was reported before, that the ultrasonographic pattern was hypodense only in $57.5 \%$ of patients, (25) and only in $54.1 \%$ of patients (26).

Most of the HCC lesions (80\%) were found in the right lobe, $(7.5 \%)$ in the left lobe of the liver and $12.5 \%$ were detected in both lobe. This was in agreement with a study which reported that HCC occurs more frequently in the right lobe of the liver either as a solitary mass or as multiple nodules $(27$, 28). This may be due to the large size of the right lobe of the liver which is 6 times larger than the left lobe

Concerning tumor size, in the present study $(90 \%)$ of $\mathrm{HCC}$ cases were $>3 \mathrm{~cm}$ and this was not in agreement with other studies who reported that the tumor size tends to be large $>5 \mathrm{~cm}$ in $85.1 \%$ and $46.3 \%$ of cases respectively, this difference may be due to large sample size in their studies, progression in diagnostic imaging modalities over years $(19,11)$

Analysis of ROC curve of serum FABP-1 revealed that FABP-1 at cut off values (214 ng/L) sensitivity was 60\%, specificity was $77.5 \%$, PPV was 72.7, NPV was $66 \%$ and $\mathrm{AUC}=0.715$. This came in agreement with study where it was reported that when a cut-off value was $29,0 \mathrm{ng} / \mathrm{mL}$ for FABP-1, sensitivity and specificity were 75 and $100 \%$, respectively. Positive and negative predictive values for FABP-1 were 100 and $78 \%$, respectively (3). These results indicate that serum FABP-1can be used as a new diagnostic marker to detect liver injury and can be used in the diagnosis of chronic 
liver diseases, including those coupled with HCC and so, serum FABP-1 can be used as a prognostic factor in chronic liver disease, as LC, and prognostic factor for survival in patients presenting with concomitant HCC.

The results of the current study indicated that serum FABP-1is a promising sensitive and specific tumor marker that could be added to the current standard tests for diagnosis of HCC and considered as the only predictor for multiplicity which indicate poor prognosis.

\section{References}

1. Heimbach Jk, Kulik LM, Finn RS, Sirlin CB, Abecassis MM And Roberts LR (2018): Aasld Guidelines For The Treatment Of Hepatocellular Carcinoma. Hepatology; 67 (1): 358-380.

2. Yang J, Li J, Dai W, Wang F, Shen M, Chen $\mathrm{K}$, et al.,(2015): Golgi protein 73 as a biomarker for hepatocellular carcinoma: A diagnostic meta-analysis. Exp Ther Med.; 9(4):1413-1420.

3. Akbal E, Köklü S , Koçak E, Çakal B, Güneş F And Başar O.(2013): Liver Fatty Acid-Binding Protein Is A Diagnostic Marker To Detect Liver Injury Due To Chronic Hepatitis C Infection. Official Journal Of The Institute Mexicano Del Seguro Social; 44 (1): 34.38.
4. Wang G, Bonkovsky HL, De Lemos A And Burczynski J.(2015): Recent Insights Into The Biological Functions Of Liver Fatty Acid Binding Protein 1. J.Lipid Res.; 56:22382247.

5. Furuhashi M And Hotamisligil GS (2008): Fatty Acid-Binding Proteins:Role In Metabolic Diseases And Potential As Drug Targets. Nat Rev Drug Disco; 7(6):489-503.

6. Li J, Dong L, Wei D, Wang X, Zhang S , Li H et al ., (2014): Fatty Acid Synthase Mediates The Epithelial-Mesenchymal Transition Of Breast Cancer Cells. Int J Biolsci ; 10:171-180.

7. Ku CY, Liu YH, Lin HY, Lu SC And Lin JY.(2016): Liver Fatty Acid-Binding Protein (L-Fabp) Promotes Cellular Angiogenesi And Migration In Hepatocellular Carcinoma. Oncotarget.;7(14):18229-18245

8. Holal NS, El-azab DS and Aiad HA (2015):Hepatocellular carcinoma in Egypt.epidemiologicalandhistopathologicalprope rties .Menoufia Medical Journal ; 28 ( 3) :718724.

9.9.Sherlock S and Dooley J (2002): Diseases of the liver and biliary system. 11th ed. , Blackwell S.C. , Oxford London, Eninburgh ; 31: $537-561$.

10. Sleisenger MF and Fordtran BF (2006): Hepatic tumors and cysts. In: Sleisenger MF and Fordtran BF (eds): Gastrointestinal and liver disease (8th edition), published by Philadelphia: W.B. Saunders ; 2( 91) : 20072028 .. 
11. Atta MM, EL Masry SA, Abdel Hameed M, Baiomy HA and Ramadan NE (2008) :Value of serum anti-p53 antibodies as a prognostic factor in Egyptian patients with hepatocellular carcinoma. Clinical Biochemsitry; 41: 1131-1139

12. Kew MC (2002):Hepatic tumors and cysts.In:Gastrointestinal and Liver Disease. Feldman M, Friedman LS and Sleisenger MH (eds.), WB Saunders, Philadelphia ;56 (8) : 1579.

13. Bolondi L, Sofia S, siring S, Gaiani S, Casali A, Zironi G, etal., (2001): Surveillance Programme of cirrhotic patients for early Diagnosis and treatment of hepatocellular carcinoma: a cost Effectiveness analysis. Gut; 48: 251-259.

14. Franca A V , Elias JJ , Lima B L,Martinelli ALand Carrilho FJ (2004): Diagnosis, staging and treatment of hepatocellular carcinoma. Braz. J. Med. Biol. Res.; 37: 1689-1705.

15. Grioco A,Pompili M and Caminiti G (2005): Prognostic factors for survival in patients with early intermediate hepatocellular carcinoma undergoing non- surgical therapy: comparison of Okuda, CLIP, and BCLC staging systems in a single Italian center. Gut.; 54: 411-418.

16. Eguchi A, Hasegawa H, Iwasa M, Tamai Y, Ohata K, Oikawa T et al ., (2019): Serum Liver-Type Fatty Acid-BindingProtein Is aPossible Prognostic Factor in Human Chronic Liver Diseases From Chronic Hepatitis to Liver Cirrhosis and Hepatocellular Carcinoma
HepatologyCommuniCations ; 39(6):825830.

17. Heindryck and Gerwins P (2015):Targeting the tumor stromainhepatocellular carcinoma. World J Hepatol ; 7:165-176.

18. El-Shenawy S, El Sabawi and Sheble N (2012) : Diagnostic Role of Serum Glypican 3 as a tumor Marker for Hepatocellular Carcinoma. Nature and Science; 10(4): 3238.

19. El-Zayadi AR, Badran HM and Barakat EM (2005): Hepatocellular carcinoma in Egypt: a single center study over a decade. World J. Gastroenterol. ; 11(33): 5193-5198.

20. Pang Q, Qu K and Zhang JY (2015): The Prognostic Value of Platelet Count in Patients with Hepatocellular Carcinoma, A Systematic Review and Meta-Analysis, Medicine (Baltimore). ; 94(37): 1431.

21. Panteghini M (2006): Enzymes. In: Teitz fundamentals of clinical chemistry, Burtis CA, Ashwood ER, Bruns DE, saunders WB, Philadelphia; (6) : 317-337.

22. LaffanM (2006): Laboratory control of anticoagulant, thrombolytic and anti-platelet therapy. In: Dacie and Lewis practical hematology, S. M. Lewis, B. J. Bain, I. Bates (Eds). Churchill livingstone co. philadelphia ; $10: 465-523$.

23. Johnson M (2006) : Amino acids and proteins. In: Teitz fundamentals of clinical chemistry ; (6) : 286-317.

24. Zheng S, Lin J, Attie AD, Keller MP, Bernlohr DA, BlanerWS,et al., (2018): Perilipin 5 and liver fatty acid binding protein functiontorestore quiescence in mouse hepatic stellate cells. J Lipid Res;59:416-428. 
Benha medical journal vol. 38, isuue 1, 20201

25. Darwish AG (2006): Assessment of Clinical Significance of Serum Squamous Cell

26. Carcinoma.M.Sc.Thesis, Tropical medicine, Cairo University ;45(4):167-72.

27. Solmi L, Premerano $M$ and Gandolfi L (1996): Ultrasound follow up of patients at risk of HCC: results of a prospective study on 360 cases. AJG;91:1189-94.
Carcinoma Antigen in Patients with Liver Cirrhosis and Hepatocellular

28. Kuntz E and Kuntz HD (2006): Malignant liver tumours. In Hepatology principles and Practice, second edition, published by Springer Verlag, Germeny ;2: 771- 809.

29. Portmann B (2004): Liver allograft pathology and biopsy interpretation. VerhDtschGesPathol; $\quad$ 88(12):29-38

To cite this article: Reda M. Albadawy, Badawy A. Abd El-Aziz, Eman G. Behiry, Maha E. Azzam. Assessment the Association of Fatty Acid Binding Protein 1 with Hepatocellular Carcinoma. BMFJ. 2021; 38(1): 1-13. DOI: 10.21608/bmfj.2020.19563.1164 